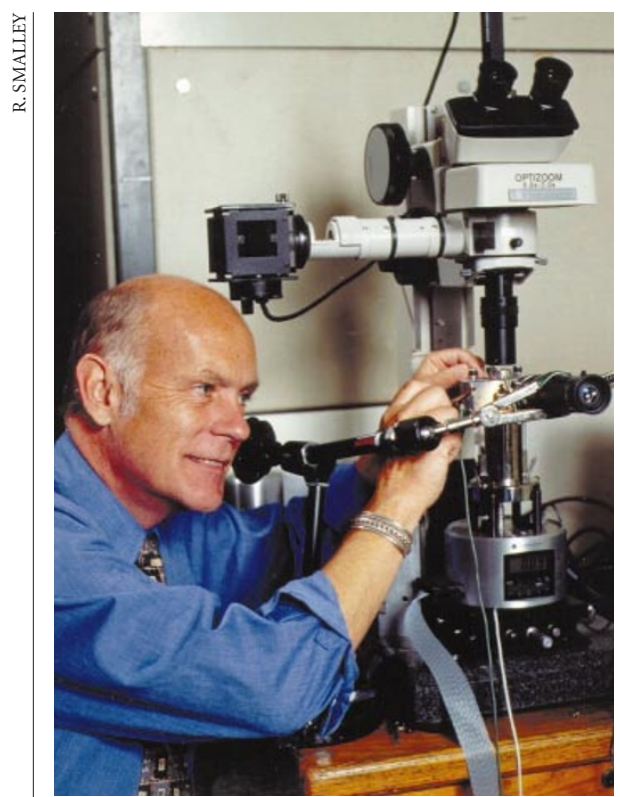

Tubular sells: Richard Smalley hopes to capitalize on nanotubes.

following the biotech model: innovations in universities, followed by spin-off companies, and eventually adaptation by larger firms.

Richard Smalley at Rice University is a case in point. Smalley shared the 1996 Nobel Prize for Chemistry for discovering buckminsterfullerene $\left(\mathrm{C}_{60}\right)$ - a new form of carbon - and its attendant family of fullerenes. Since then, he has begun manufacturing a tubular version of the carbon macromolecules. He is now set to step up production with his new company, Carbon Nanotechnologies.

Initially, the company will remain small, at around 25 employees. It will focus on producing tubes for researchers who might use them to make polymers, medical devices or to build circuits. The company might eventually try some of those applications on its
own."But right now we just want to make the stuff," says Smalley.

Dow Chemical, on the other hand, is testing the potential of using clay nanoparticles in polymers. The company has a small programme - \$16 million over five years, half of which comes from the US National Institute of Standards and Technology - to design plastics that evenly incorporate nanoparticles.

"The target here is to design plastics that have the behaviour of metals," says Juan Garces, a senior research scientist at Dow. He hopes to be able to coax the particles to selfassemble and so disperse evenly into the polymer matrix. Because the clay nanoparticles have a higher ratio of atoms on their surface than do larger clay molecules, he expects the composite formed to withstand higher temperatures than conventional polymers. But expanding this programme so that it generates more jobs relies on more than just scientific success - it must also make money.

\section{Instrumental technology}

One application for nanotechnology that is potentially profitable is in medical testing devices, notably those that can read small amounts of DNA. This has attracted university researchers and resulted in a number of spin-offs.

Chad Mirkin, director of Northwestern University's Institute for Nanotechnology incorporated his company, Nanosphere (based in Evanston, Illinois), last January, out of his research on using DNA to aid selfassembly. The company, which has eight employees and is on track to double this figure in a year, aims to produce particles that will bind specifically to minute quantities of DNA, which could then be used as very sensitive probes for disease.

One of the company's staff scientists, James Storhoff, says the company epitomizes

\title{
Building for the future
}

If universities are to be the engines for powering nanotechnology, then new facilities may be the sparkplug. So far only one institution, Rice University, has what Stanley Williams, a senior principal lab scientist at HewlettPackard Laboratories in California, calls true nanotechnology capabilities - the resources to produce and analyse materials smaller than 100 nanometres.

But several universities are planning to build such facilities. Harvard's proposal drew Charles Marcus from a tenured position at Stanford, even though the Harvard project has not yet broken ground. Although the National Science Foundation funds several nanofabrication centres, "you have to wait in line", says Marcus.

Northwestern University's Institute for Nanotechnology will get its own \$34 million building in 2002. And the University of California at Los Angeles, partnering with the University of California at Santa Barbara, is hoping to receive state funds for a $\$ 360$ million facility. Williams says the completion of those buildings will coincide with when he expects the job market in nanotechnology to take off - the next five to ten years. Just as biotech companies spun out of the boom of life science research over the past ten years, he expects nanotech companies to emerge from university nanotech programmes as they continue to expand.

Center For Nanoscale Science And Technology at Rice University http://cnst.rice.edu
Northwestern University Institute for Nanotechnology /http://www.northwestern.edu/ research/nanotechnology/ index.html facilities http://deas.harvard.edu/ jones/ lab_arch/nano_facilities/ nano_facilities.html

how truly multidisciplinary nanotechnology can be. Physical chemists look at the properties of different materials to work out which will make the best nanoparticle for a particular application. Organic chemists then find ways to attach the DNA pieces to the particles. Biologists look primarily at the DNA to

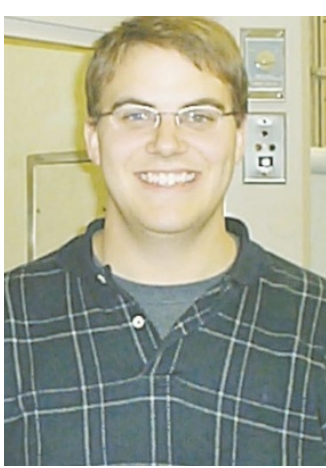

James Storhoff recognizes the interdisciplinary nature of nanotech. the greatest promise of long-term job prospects: developing computer chips with ever-smaller circuitry. "Lithography is going to reach a limit," says Thomas Theis, head of physical sciences at IBM's Thomas J. Watson Center in Yorktown, New York.

So instead of carving away at a chip, the next step will be to build circuitry from the ground up, perhaps using DNA to put the switches in place. IBM has probably the largest nanocomputing groups in the world with 40-60 'hardcore' nanotechnology researchers.

IBM built such a large team because the company realized that processing speed and storage space could not keep increasing without a technical shift. The same impetus is driving DuPont iTechnologies, which makes material for integrated circuits, and Agilent, to invest more in basic research.

Agilent is rebuilding its basic research group after splitting with Hewlett-Packard last November. The group functions more like an academic team, and is judged more on publication than on product, says Len Cutler, director of precision instrumentation and basic research at Agilent in Palo Alto. The team now has seven members, but the company would like to double that. Agilent, like so many other companies, is poised to take advantage of the nanotech boom, but remains cautious of investing too much too soon.

Paul Smaglik is Nature's correspondent in Washington DC and Careers and Recruitment editor.

National Nanotechnology Initiative

http://wwww.nano.gov

Carbon Nanotechnologies

http://www.cnanotech.com

Nanosphere

http://www.nanosphere-inc.com

Nanogen

http://www.nanogen.com/www1/index.htm 